\title{
Parents experienced cycles of defining and managing adversity in caring for a child with a chronic progressive illness
}

\author{
Gravelle AM. Caring for a child with a progressive illness during the complex chronic phase: parents'experience of facing \\ adversity. J Adv Nurs 1997 Apr;25:738-45.
}

\section{Objective}

To describe parents' day to day experiences as they manage their child's chronic, life threatening, progressive illness.

\section{Design}

Phenomenology.

\section{Setting}

Community study in British Columbia, Canada.

\section{Participants}

11 parents (5 mothers and 3 couples; 1 mother divorced, all others married) of 8 children volunteered through the Muscular Dystrophy Association of Canada and 2 community health departments. Children were 2.2-16 years old; lived at home; and had Duchenne's muscular dystrophy, spinal muscular atrophy type II, metachromatic leucodystrophy, Rett's syndrome, or cerebral palsy with microcephaly and respiratory distress. The children were not in the terminal phase of illness, but required specialised and time consuming care.

\section{Methods}

Parent interviews occurred in the home, were audiotaped, and transcribed for analysis. Initial interviews (8 parents) were unstructured with trigger questions; second interviews (5 parents) clarified and validated initial findings. Data saturation occurred after 8 first interviews.

\section{Main results}

Parents reported successive hardships and challenges because of the progressive nature of their child's illness. They experienced cycles of defining and managing adversity which were repeated with each important change.
Defining adversity was shaped, firstly, by characteristics of the condition (extent of illness, rate of progression, number of affected children in the family, child's age, and developmental stage); secondly, by family characteristics (ways parents perceived the illness, their acceptance of the condition, the sorrow and grief prompted by feelings of loss, and the strength gained from facing the progression of the illness); and thirdly, by the magnitude of effect of some situations (eg, transition from walking to wheelchair).

After facing adversity came managing adversity. This consisted of 4 steps: seeking information on the illness, required equipment, and services; planning and preparing for the future; negotiating for special services and free time; and arranging resource use (respite care, special services, funding, support systems, and community education). The health care system was seen both as necessary and frustrating. All parents wanted normality and most worked for it. Adjustment to the progressive losses was constant and involved chronic sorrow. Mothers assumed the major responsibility for managing the adversity. Societal expectations and forced personal choices were associated with burnout, exhaustion, resentment, and frustration.

\section{Conclusions}

Parents experienced cycles of defining and managing adversity as they cared for children with chronic, life threatening, progressive disease. Sorrow and stress were present as they adapted to the progressive nature of the disease.

Source of funding: not stated.

For article reprint: Ms A M Gravelle, Cystic Fibrosis Programme, Room 2C66, British Columbia's Childrens Hospital, 4480 Oak Street, Vancouver, British Columbia V6H 3V4, Canada. Fax +1 604 8752349 .

\section{Commentary}

This study by Gravelle contributes valuable knowledge to the area of caring for a child with a chronic condition. The investigator focused on the time when the child is in need of specialised and time consuming care, and described the stresses and concerns experienced by parents. Her findings are consistent with those of other researchers who describe the experiences, concerns, and tasks that are part of the day to day life of these families. ${ }^{12}$ The information adds to a base for nurses to shape their assessments. Assessments should include the family's situation and a determination of how parents define and manage their adversity. Ongoing assess- ment should be done to identify and respond to the changing needs of families. Given that the need for respite care became crucial to parents, nurses have an important role in anticipating and attending to respite needs. In the absence of an organised system to provide respite care, alternative support care programmes need to be developed or strengthened. The author collected data to provide direction for the implementation of services in care settings. Two conditions of such settings implicit in the parents' descriptions of their needs included availability and continuity. Nurses working in settings where the context of the health care system is shifting are finding these conditions difficult to meet.

Elizabeth Kauffmann, RN, MEd Assistant Professor, School of Nursing Queen's University Kingston, Ontario, Canada

1 Deatrick JA, Knafl KA, Guyer K. The meaning of caregiving behaviours: inductive approaches to family development. In: Feetham SL, Meister SB, Bell JM, Gilliss CL, eds. The nursing of families: theory, research, education,

2 Burke SO. Kauffmann E, Wiskin N, et al. Burke SO. Kauffmann E, Wiskin $\mathrm{N}$, et al.
Children with chronic illnesses and their parChildren with chronic illnesses and their par-
ents in the community. In: Stewart MJ, ed. ents in the community. In: Stewart Mj, ed. health. Toronto: W B Saunders, 1995:284-313. 